\title{
Vorwort zur 3. Auflage
}

Für die Neuauflage erfolgte eine umfassende Einarbeitung der zahlreichen steuerlichen Neuregelungen, wobei im Ergebnis - auch bezüglich der zahlreichen Beispiele und Übungsaufgaben - der Rechtsstand des Jahres 2017 relevant ist, auf schon feststehende Neuerungen im Jahr 2018 und später aber hingewiesen wird.

Mein großer Dank gilt dem verantwortlichen wissenschaftlichen Mitarbeiter, Herrn DANIEL LICHT, M.Sc., für die von Zielstrebigkeit und Kompetenz getragene Unterstützung bei der inhaltlichen Überarbeitung und der formalen Gestaltung (inklusive der Erstellung einer Druckvorlage für den Verlag). Frau HeIKE MANG gilt mein Dank für die erstklassige Unterstützung im Umfeld der Publikation, Herrn Dr. Stefan GIESEN und Frau AnNeTte Huppertz für die lektoratsmäßige Betreuung beim Verlag. 